\title{
Diálogos em modelagem matemática
}

\author{
Dialogues in mathematical modeling
}

Elaine Cristina Ferruzzi ${ }^{1}$ • Lourdes Maria Werle de Almeida ${ }^{2}$

Resumo: Neste artigo, apresentamos parte dos resultados de uma pesquisa em que investigamos o papel da Modelagem Matemática para o estabelecimento de interações cujas características favorecem a aprendizagem. Diante da importância atribuída à comunicação em atividades de Modelagem Matemática e às interações em sala de aula, investigamos as interações que emergem durante o desenvolvimento de atividades de Modelagem e procuramos identificar interações classificadas por alguns pesquisadores como sendo aquelas associadas à aprendizagem. As análises que apresentamos indicam que aquelas interações identificadas durante o desenvolvimento das atividades que podem ser caracterizadas como 'diálogos' favorecem a aprendizagem dos alunos. Subsidiamos nossas conjecturas na análise de atividades desenvolvidas por um grupo de alunos de um curso de Engenharia Ambiental de uma universidade pública.

Palavras-chave: Educação matemática. Modelagem matemática. Ensino Superior. Diálogo.

Abstract: This article presents part of the results of a research project that investigated the role of Mathematical Modeling for the establishment of interactions whose characteristics can promote learning. Given the importance attributed to communication in Mathematical Modeling activities and interactions in the classroom, we investigated the interactions that emerge during the development of modeling activities and sought to identify the interactions classified by some researchers as those associated with learning. The analyses we present indicate that those interactions identified during the development of activities which can be characterized as "dialogues" favor the students' learning. We base our assumptions on the analysis of activities developed by a group of students in an Environmental Engineering course at a public university.

Keywords: Mathematical education. Mathematical modeling. Higher education. Dialogue.

\footnotetext{
${ }^{1}$ Universidade Tecnológica do Paraná (UTFPR), Avenida dos Pioneiros, 3131, CEP 86036-370, Londrina, PR, Brasil. E-mail: <elaineferruzzi@utfpr.edu.br>

${ }^{2}$ Centro de Ciências Exatas, Universidade Estadual de Londrina (UEL), Londrina, PR, Brasil.
} 


\section{Introdução}

A dificuldade encontrada por alunos de cursos de engenharia na aprendizagem da matemática tem sido assunto recorrente em publicações da área de Educação Matemática. A relação dessa dificuldade e o nosso entendimento de que a Educação Matemática deve ir além do ensino da matemática, por si só, têm nos conduzido a investigação de metodologias que possam auxiliar o aluno em seu processo de aprendizagem.

Em nossas pesquisas, encontramos os estudos de Vigotsky (1993), para quem a aprendizagem está diretamente associada à interação e, ancorados em suas ideias, vários pesquisadores têm investigado e apresentado argumentos favoráveis à introdução de metodologias que oportunizem interações em sala de aula.

Além da importância atribuída à introdução destas metodologias, alguns pesquisadores, entre eles Alro e Skovsmose (2006), apontam que algumas interações contribuem mais do que outras para a aprendizagem dos alunos.

Estes autores referem-se a estas interações como "diálogos". De acordo com Alro e Skovsmose (2006), interações caracterizadas como "diálogos” são interações que possuem qualidades que influenciam positivamente a aprendizagem.

Assim, com o objetivo de corroborar com os argumentos favoráveis à inserção da Modelagem Matemática em sala de aula, investigamos algumas interações que emergem durante o desenvolvimento de atividades de Modelagem em sala de aula, procurando identificar a ocorrência de "diálogos", como caracterizados por Alro e Skovsmose (2006).

Em nossa pesquisa, apresentada em Ferruzzi (2011), analisamos 18 interações, sendo que, destas, 11 foram caracterizadas como "diálogo", nos levando a corroborar com as argumentações favoráveis à Modelagem Matemática em sala de aula.

Neste artigo, apresentamos e analisamos, à luz do quadro teórico, três destas interações.

\section{Quadro teórico}

\section{Interações em atividades de Modelagem Matemática}

Entendemos Modelagem Matemática como a busca por uma representação matemática para um objeto ou fenômeno que pode ser matemático ou não. "Neste sentido, trata-se de um procedimento criativo e interpretativo que estabelece uma estrutura matemática que deve incorporar as características essenciais do objeto ou fenômeno que pretende representar" (ALMEIDA; FERRUZZI, 2009, p. 120).

Considerando que a construção desta representação pode ocorrer em sala de aula, muitos educadores da área de Educação Matemática têm apresentado argumentos favoráveis à sua introdução em sala de aula. Esta introdução tem sido pontuada sob diferentes justificativas, levando em consideração: a reflexão dos alunos sobre o papel da Matemática na sociedade (OLIVEIRA; CAMPOS; SILVA, 2009; SKOVSMOSE, 2001); a aprendizagem de conceitos matemáticos (ALMEIDA; FERRUZZI, 2009; CHINNAPPAN; THOMAS, 2003; SANT'ANA, 2007); a oportunidade para o aluno exercer um papel investigativo (ALMEIDA; FERRUZZI, 2009; SANTOS; BISOGNIN, 2007); a motivação para a aprendizagem (SANTOS; BISOG- 
NIN, 2007); o desenvolvimento da capacidade de solucionar problemas oriundos do cotidiano (BISOGNIN; BISOGNIN; ALONSO RAYS, 2004); o uso das tecnologias de comunicação e informação (BORBA; MALHEIROS, 2007), entre outras.

No encaminhamento dado às atividades de Modelagem Matemática em sala de aula, os envolvidos realizam ações, como: a busca por informações sobre o fenômeno a ser estudado; a identificação e seleção de variáveis; a elaboração de hipóteses; a simplificação do problema; a obtenção e validação de um modelo matemático. Estas ações, geralmente, são realizadas em grupo, e os encontros (interações entre alunos e entre professor/alunos) que ocorrem nestas atividades têm sido pontuados, por diversos pesquisadores, como determinantes para a aprendizagem.

Fox (2006), por exemplo, considera que, sendo as atividades de Modelagem projetadas para serem desenvolvidas em pequenos grupos, os alunos desenvolvem e compartilham conceitos, explicações, justificativas e representações matemáticas, e, deste modo, estas atividades oportunizam a colaboração social e o desenvolvimento de habilidades de comunicação. O autor considera, ainda, que, em atividades de Modelagem Matemática, as pessoas discutem, debatem, aperfeiçoam suas ideias, ouvem e colaboram com seus pares e, quando apresentam o modelo final para os colegas, comunicam suas ideias matemáticas, e, deste modo, ocorrem oportunidades para o questionamento crítico e a justificação.

Zbiek e Conner (2006) também consideram que os estudantes aprendem quando trabalham em interação em Modelagem Matemática. Para as autoras, a reflexão que o indivíduo faz quando está se comunicando com os outros conduz o indivíduo a modificar ou justificar seu procedimento e seu entendimento do conceito matemático por ele utilizado. Observamos que estas características apontadas por Fox (2006) e Zbiek e Conner (2006) vão ao encontro de um dos nossos objetivos, que consiste em contribuir com a formação geral do indivíduo.

Destacamos que estas ideias convergem para a perspectiva de Vigotsky (1993), para quem o conhecimento é construído "na" e "pela" interação. Os estilos de comunicação, as ferramentas empregadas e a forma como o conhecimento pode ser construído por meio destas interações, trazem contribuições para a formação do aluno.

Ainda que as argumentações dos autores aqui apresentados sinalizem a ocorrência e importância de interações em atividades de Modelagem Matemática, procuramos investigar características nestas interações que possam contribuir com estas argumentações, procurando identificar a ocorrência de "diálogo" como caracterizado por Alro e Skovsmose (2006).

\section{Interações como um "diálogo"}

Com vistas a uma educação matemática que promova, além da aprendizagem dos conceitos matemáticos, habilidades para sua aplicação e reflexão acerca da confiabilidade destas aplicações, Alro e Skovsmose (2006) discutem, no livro "Diálogo e aprendizagem em educação matemática”, qualidades da comunicação que podem influenciar certas qualidades da aprendizagem. Neste estudo, os autores orientam suas investigações sob a hipótese inicial de que a qualidade da comunicação em sala de aula influencia a qualidade da aprendiragem da matemática. Os autores consideram ainda que esta qualidade da comunicação pode ser expressa em termos de relações interpessoais, uma vez que aprender 
[...] é uma experiência pessoal, mas ela ocorre em contextos sociais repletos de relações interpessoais. E por conseguinte a aprendizagem depende da qualidade do contato nas relações interpessoais que se manifesta durante a comunicação entre os participantes. (ALRO; SKOVSMOSE, 2006, p. 12)

Estes autores argumentam que algumas qualidades da comunicação podem ser explicadas em termos de "diálogo", assumindo que "diálogo" é uma conversação com certas qualidades. Este termo é entendido pelos autores como uma conversação que visa a aprendizagem, em que os participantes "se encontram", influenciando e sofrendo mudanças.

Com base nas argumentações de Paulo Freire (1972 apud ALRO; SKOVSMOSE, 2006), os autores advertem que, em um "diálogo", não podem existir relações de dominação, e os participantes desta conversação específica precisam acreditar uns nos outros e possuir um engajamento, uma cooperação entre as partes. Um "diálogo" é uma forma humilde e respeitosa de cooperação, e é motivado por expectativas de mudança; deste modo, o engajamento é fundamental e a cooperação é "[...] um parâmetro central da comunicação dialógica” (ALRO; SKOVSMOSE, 2006, p. 14).

Isto posto, Alro e Skovsmose (2006, p. 16) pontuam "certos aspectos da comunicação que podem apoiar certos aspectos da aprendizagem" e preconizam o "diálogo" como uma ferramenta para o sucesso da aprendizagem, apresentando três de suas características associadas à aprendizagem: (1) realizar uma investigação; (2) correr riscos, e (3) promover a igualdade.

O primeiro aspecto, realizar uma investigação, significa que o "diálogo", como caracterizado pelos autores, é uma conversação de investigação com o objetivo de obter conhecimentos e novas experiências. Realizar uma investigação significa explorar perspectivas, ter curiosidade, estar disposto a considerar o pensamento e as perspectivas do "outro".

Realizando uma investigação, o sujeito abandona sua posição cômoda e pode entrar em um processo cujo resultado final dependerá de sua disposição e curiosidade. Segundo os autores

Alguns atos investigativos são identificados: explicar, elaborar, sugerir, apoiar, avaliar conseqüências. Eles são identificados como atos investigativos pois constituem tentativas de ir além, e ajudam outros a ir além do seu pensamento estabelecido. Neste sentido, investigar atua no campo que está entre o-que-se-sabe e o-que-ainda-não-se-sabe ou numa Zona de Desenvolvimento proximal [...]. (ALRO; SKOVSMOSE, 2006, p. 124. Grifo do autor)

Esta característica credita, ao "diálogo" (realizar uma investigação), um caráter de imprevisibilidade, conduzindo ao segundo aspecto apontado pelos autores: correr riscos.

"Correr riscos" é uma forma de expressar a natureza imprevisível do encaminhamento e desdobramentos de um diálogo. No "diálogo" entre professor e alunos, esse deve assumir um papel de orientador, de modo a assegurar que, em razão da imprevisibilidade, os alunos não se desviem do foco principal, evitando, assim, a sua desistência. "Dialogar é arriscado, na medida em que pode mexer com sentimentos ruins, bem como causar alegria" (ALRO; SKO- 
VSMOSE, 2006, p. 128). Neste sentido, o professor deve estar atento à "falta de rumo" que o aluno pode sentir.

Numa sala de aula, os alunos podem parecer envolvidos numa atividade, sugerindo produtividade, mas, na verdade, podem estar perdidos. Neste caso, uma investigação pode incomodar. Para que o diálogo aconteça em um ambiente educacional, é importante que o desconforto não seja exagerado, pois os alunos podem ficar frustrados, chegando ao ponto de desistir. O importante é não remover o risco, mas estabelecer um ambiente de aprendizagem confortável e respeitoso e uma atmosfera de confiança mútua, nos quais se torna possível experimentar incertezas passageiras (ALRO; SKOVSMOSE, 2006, p. 129).

Diversas opções metodológicas que desafiam o ensino centrado no paradigma do exercício, em que aulas expositivas são seguidas de exercícios associados a esta exposição de conteúdos, têm sido, cada vez mais, inseridas e desenvolvidas em sala de aula de Matemática. Alro e Skovsmose (2006) defendem esta inserção, e consideram que perspectivas que adotam uma abordagem investigativa são propícias para abrir espaços para novas comunicações, conduzindo a novas qualidades da comunicação à medida que os alunos tornam-se condutores da sua aprendizagem. Para estes autores, "Novas qualidades de aprendizagem tornam-se possíveis quando novas possibilidades de comunicação tornam-se presentes” (ALRO; SKOVSMOSE, 2006, p. 75).

O terceiro aspecto do "diálogo" apontado pelos autores, promover a igualdade, refere-se a um relacionamento interpessoal, essencial para o diálogo como aqui caracterizado. Para os autores, promover a igualdade não significa negar as diferenças e diversidades, e sim, saber lidar com elas. "Participar de um diálogo é algo que não deve ser imposto a ninguém. Em sala de aula, isso significa que o professor pode convidar os alunos para um diálogo investigativo, mas eles têm de aceitar o convite para que o diálogo aconteça” (ALRO; SKOVSMOSE, 2006, p. 131-132).

A caracterização apresentada pelos autores para o termo "diálogo" como uma conversação que compreende realizar uma investigação, correr riscos e promover a igualdade, mostra, de acordo com os autores, algumas qualidades identificadas idealmente, porém, imprescindíveis para que a interação seja considerada como tal.

A segunda caracterização de "diálogo" apresentada por Alro e Skovsmose (2006, p. 135) é "[...] um processo envolvendo atos de estabelecer contato, perceber, reconhecer, posicionar-se, pensar alto, reformular, desafiar e avaliar". Esta caracterização foi desenvolvida com base na análise de processos de comunicação e foi construída em termos de "atos dialógicos". Para os autores, "atos dialógicos" são atos da fala com características especiais, e envolvem, no mínimo, duas pessoas em uma relação de igualdade.

$\mathrm{Na}$ sequência, apresentamos uma síntese das principais características destes atos dialógicos enunciadas por Alro e Skovsmose (2006).

\section{1) Estabelecer contato}

Criar uma sintonia com o colega em interação e "estar presente e prestar atenção ao outro e as suas contribuições” (ALRO; SKOVSMOSE, 2006, p. 106). Estabelecer contato torna os participantes abertos à investigação. Este estabelecimento pode ser observado por meio de: apoio, questões investigativas acompanhadas de retorno, confirmações recíprocas, preocupação com o entendimento do "outro" etc. O uso do pronome pessoal na primeira pessoa do plural indica que os participantes do discurso estão trabalhando conjuntamente. 


\section{2) Perceber}

Na perspectiva de "diálogo" adotada por Alro e Skovsmose (2006), perceber significa descobrir algo de que não se tenha conhecimento ou examinar como o "outro" entende certo problema, e isto inclui questionar suas próprias concepções e examiná-las conjuntamente com o outro, aceitando-as ou rejeitando-as.

Com vistas a perceber de forma apropriada a perspectiva do outro e sua própria perspectiva, o ato de perceber vem acompanhado de questões que buscam: explicações, investigação, possibilidades, questões hipotéticas e questões abertas nas quais não se conhecem as respostas antecipadamente.

$\mathrm{Na}$ resolução de um problema conjuntamente (assim como individualmente), podem surgir ideias interessantes e relevantes que são deixadas de lado ou, simplesmente, ignoradas, pelo simples fato de não terem sido percebidas. Em um processo individual, o aluno deverá estabelecer um diálogo consigo mesmo para ter chances de perceber estas ideias. Em processos interativos, as chances aumentam.

\section{3) Reconhecer}

Observar com atenção "perspectivas e idéias que foram percebidas abre o caminho para que se reconheça uma perspectiva e a faça conhecida de todos os envolvidos na investigação" (ALRO; SKOVSMOSE, 2006, p. 109. Grifo do autor). A busca do professor na tentativa de reconhecer o princípio ou procedimento que o aluno pretende utilizar conduz o estudante a justificar seu raciocínio ou procedimento, guiando-o em seu reconhecimento. O professor, como participante do diálogo, pode auxiliar o aluno com questões do tipo "por quê", conduzindo-o a delinear suas ideias matemáticas.

\section{4) Posicionar-se}

Posicionar-se significa dizer o que se pensa, fazer declarações ou apresentar argumentos, e, ao mesmo tempo, aceitar críticas às suas sugestões e seus pressupostos, com o intuito de investigar conjuntamente um assunto ou perspectiva.

Não significa tentar convencer o outro de sua posição (até por que um diálogo é permeado de respeito), e sim, estar aberto às outras perspectivas e à reavaliação de seu ponto de vista. Para o bom andamento de um diálogo e tentativa de construir uma perspectiva comum, é essencial compartilhar o que se sabe, e, neste sentido, ideias devem ser ouvidas e argumentos analisados.

\section{5) Pensar alto}

Pensar alto é uma forma de tornar o pensamento público e, neste sentido, auxilia o "outro" a entender como um indivíduo está pensando, sendo possível observar se as perspectivas coincidem ou estão no mesmo caminho. Pensar alto também faz com que o "outro" acompanhe seu raciocínio: “[...] significa expressar pensamentos, idéias e sentimentos durante o processo de investigação. Expressar o que se passa dentro de si expõe as perspectivas à investigação coletiva" (ALRO; SKOVSMOSE, 2006, p. 113).

Pensar alto surge, geralmente, na manifestação de pensamentos e sentimentos, e na forma de questões hipotéticas.

\section{6) Reformular}

O sentido de reformular atribuído pelos autores é o mesmo sentido do termo parafrasear, ou seja, repetir algo que foi dito com outras palavras. Neste sentido, repetição de termos, ideias, sugestões de outros participantes, podem ser utilizadas para confirmar o que se ouviu, como um convite para uma reflexão maior, ou confirmação de que possuem o mesmo entendimento, 
ou, ainda, delimitar divergências. Para os autores, "Reformular nesse sentido é um elemento importante no processo de escuta consciente, no qual os participantes seguem de perto os demais, a fim de conhecer as perspectivas uns dos outros" (ALRO; SKOVSMOSE, 2006, p. 115).

Muitas vezes, a reformulação é feita pelo próprio emissor, com o intuito de se fazer entender pelo "outro". Quando um aluno reformula o que o outro falou e toma para si aquela perspectiva, indica que a responsabilidade pelo processo está sendo dividida. Neste sentido, reformular pode ocorrer parafraseando, completando-se falas e mantendo contato.

\section{7) Desafiar}

Desafiar significa tentar modificar a direção do encaminhamento do processo ou questionar conhecimentos ou perspectivas já estabelecidas. Desafios, geralmente, vêm acompanhados de questões hipotéticas, “o que acontece se”, conduzindo os participantes à reanálise de propostas já estabelecidas e ao exame de novas possibilidades. Além do reexame de perspectivas, desafios podem ocorrer por meio de um novo posicionamento. Um desafio tem grandes chances de iniciar uma nova investigação, mesmo que seja para refutar a ideia proposta.

Como salientam Alro e Skovsmose (2006), um desafio cumpre seu papel mesmo que seja refutado com um bom argumento. Neste caso, entraria em cena o posicionamento.

\section{8) Avaliar}

Uma avaliação pode assumir muitas formas. Correção de erros, crítica negativa, crítica construtiva, conselho, apoio incondicional, elogio ou novo exame - é uma lista incompleta. Uma avaliação pode ser feita por terceiros ou pelo próprio indivíduo. (ALRO; SKOVSMOSE, 2006, p. 116. Grifo do autor)

Para os autores, avaliar pressupõe feedback, apoio e críticas construtivas.

Os oito atos dialógicos representam aspectos de um mesmo processo de investigação, ou seja, quando se busca analisar um diálogo, de modo geral, não é possível observá-los separadamente, mesmo porque um pode estar inserido no outro.

\section{Nossa pesquisa}

Os resultados apresentados neste artigo são parte de uma pesquisa mais ampla, descrita em Ferruzzi (2011). Para este artigo, estabelecemos, como foco de análise, atividades de Modelagem Matemática desenvolvidas por um grupo de alunos matriculados na disciplina Matemática 2, no segundo ano do curso de Engenharia Ambiental de uma Universidade Tecnológica Federal. Para o desenvolvimento das atividades, os 14 alunos da turma foram divididos em quatro grupos. Esta divisão foi realizada pelos próprios alunos, de acordo com suas preferências, não tendo interferência da professora/pesquisadora. A atividade que analisamos neste artigo foi desenvolvida pelo grupo 1, formado por quatro alunos.

A escolha por este curso deu-se pelo fato de que as atribuições do futuro engenheiro ambiental requerem do aluno: a realização de atividades que lhe permitam solucionar problemas; trabalhar em equipe; comunicar-se adequadamente; perceber e compreender o papel da matemática na solução de problemas, tanto ambientais quanto sociais; desenvolver um pensa- 
mento crítico em relação à confiabilidade dos resultados matemáticos, com vistas ao bem-estar do indivíduo e a conservação da natureza. Neste sentido, inferimos que a participação destes estudantes em atividades de Modelagem Matemática no decorrer do curso poderá contribuir para seu sucesso tanto acadêmico quanto profissional.

\section{A coleta dos dados}

Os dados foram obtidos por meio de quatro instrumentos de coleta: filmadora, gravadores, material produzido pelos alunos e notas de campo elaboradas pela professora/pesquisadora. As interações ocorridas durante o desenvolvimento destas atividades foram gravadas em áudio e vídeo, transcritas e analisadas em nossa pesquisa.

\section{A condução das análises}

As análises dos dados são realizadas frente ao nosso objetivo, que consiste em identificar características das interações que nos levam a inferir que estas interações podem ser caracterizadas como "diálogo" na perspectiva de Alro e Skovsmose (2006).

Para efetuar estas análises, transcrevemos as gravações (de áudio e vídeo) e comparamos com as notas de campo, com o intuito de acrescentar algo que não foi observado nas gravações. As imagens e sons obtidos foram ainda comparados com o material escrito pelos alunos.

\section{Interações caracterizadas como "diálogo"}

Diante do objetivo deste texto, apresentamos, neste item, uma síntese do desenvolvimento de uma atividade de Modelagem Matemática com três interações analisadas, sendo duas delas consideradas "diálogos", e a terceira não.

A situação-problema que discutimos neste artigo diz respeito à variação da concentração de cálcio em sedimentos de fundo do Rio Limoeiro, localizado em cidade do norte do Paraná, cuja água é usada para abastecimento de algumas regiões da cidade.

Problema de estudo: estudar a variação da concentração de cálcio em sedimentos de fundo do Rio Limoeiro (Londrina, PR), cuja água é utilizada para abastecimento de algumas regiões da cidade.

Variáveis: profundidade do rio: $p$ (em cm); concentração de cálcio em função da profundidade: $C(p)$.

Tabela 1. Concentração de cálcio em relação à profundidade do rio Limoeiro

\begin{tabular}{lc}
\hline Profundidade do rio $(\mathbf{c m})$ & Concentração de cálcio $(\mathrm{g} / \mathrm{cm} 3)$ \\
\hline 30 & 2,958397 \\
90 & 2,3163 \\
150 & 1,64139 \\
210 & 1,2647 \\
330 & 0,6041 \\
\hline
\end{tabular}

Fonte: Borssoi (2004). 
Hipótese

$\boldsymbol{H}_{1}=$ a taxa de variação da concentração do cálcio em relação à profundidade do rio é proporcional à quantidade de cálcio em cada profundidade.

Modelo matemático associado à hipótese $\frac{d C}{d p}=k C$

Este tema mostrou-se pertinente e despertou interesse dos alunos, proporcionando grande participação nas discussões, visto que o mesmo diz respeito a um tema voltado à futura profissão destes estudantes.

Esta atividade foi desenvolvida durante duas horas/aulas, iniciando-se com uma interação entre professora e alunos, com a intenção de diagnosticar o conhecimento dos alunos sobre o tema e, ao mesmo tempo, motivá-los para a investigação do problema. A Interação 1 apresenta a discussão estabelecida neste momento.

\section{Interação 1}

Prof: Então turma, como combinamos hoje vocês vão me ajudar a resolver um problema...

A1: então é hoje que começo a ficar famoso!! [risos dele e de toda a turma].

Prof: $e$ sim... [risos]

Prof: Eu trouxe "prá" vocês alguns dados sobre a concentração de cálcio em diferentes profundidades do rio Limoeiro... Vocês sabem qual é o rio Limoeiro?

A4: é um rio daqui de Londrina.

Prof: e o que mais você sabe deste rio?

A4: ah... mais nada... é que ouvi falar na tw...

A1: "prof" acho que a água dele vai para a Sanepar

Prof: prá Sanepar?

A1: é... prá abastecer a cidade

Prof: certo... a água do Rio Limoeiro é uma das fontes de abastecimento de Londrina.

Uma das né? Tem outras. Alguém sabe de mais alguma?

A4: acho que do Tibagi... do Cafezal...

Prof: certo... obrigada. Então pessoal, eu trouxe uns dados referentes à concentração de cálcio no rio Limoeiro. Por que se interessar por estes dados? Qual a importância de estudar esta situação?

A6: porque a gente vai beber essa água...

A9: $e$ a quantidade de cálcio pode ser perigosa.

Prof: Perigosa? Por que A9?

A9: porque o excesso faz mal a saúde... pode causar pedras no rim.

A7: e também é ruim para a natureza por causa da dureza da água.

Prof: dureza da água?? O que é isso?

A7: ah... não pode beber "água dura", nem lavar roupa...

Prof: por que? não pode usar nem prá lavar roupa?

A7: não é que não pode, é que como precisa de mais sabão para formar espuma, prejudica o meio ambiente.

A13: Mas o cálcio também é bom para a saúde. 
Prof: explique melhor A13.

A13: ah "prof"... o cálcio é bom prá formar os ossos e dentes...

A12: para o crescimento...

Prof: alguém discorda? Alguém quer falar mais alguma coisa?

Os alunos indicam que concordam com o que foi dito até agora e não fazem menção a acrescentar mais nada.

Prof: então o cálcio é bom, mas não pode ser em excesso certo? É isso?

Alunos: é.

Prof: ok pessoal...

A1: [interrompendo a fala da professora] to gostando desta aula de matemática... [risos]. [Os demais alunos riem do comentário do colega e concordam com ele, dizendo que "não parece aula de matemática"].

Prof: Bem pessoal, vamos ver o que podemos fazer com estes dados que eu trouxe... Vou entregar para vocês e vejam o que podemos estudar com eles.

\section{Análise da Interação 1}

A intenção de estabelecer contato é evidenciada, nesta interação, pelo uso de expressões do tipo: é isso?, certo?, concordam? etc. O uso destas expressões evidencia, ainda, uma forma de convite à participação (ALRO; SKOVSMOSE, 2006). Professora e alunos buscam criar uma sintonia, estando presente, prestando atenção um ao outro e às suas contribuições.

No início da interação, a professora se apresenta como parte da equipe, quando sugere que os alunos a ajudarão a solucionar o problema. Deste modo, coloca-se como participante do grupo, sugerindo que a responsabilidade é de todos, e não apenas dos alunos ou da professora, estabelecendo um contato com o grupo.

Considerando que as falas 14 e 15 [A6: porque a gente vai beber essa água... A9: e a quantidade de cálcio pode ser perigosa], 17 e 18 [A9: porque o excesso faz mal a saúde... pode causar pedras no rim. A7: e também é ruim para a natureza por causa da dureza da água], 25 e 26 [A13: ah "prof"... o cálcio é bom prá formar os ossos e dentes... A12: para o crescimento...] apresentam um aluno completando as ideias do outro, indicando que os estudantes estão em conjunto na conversação, estabelecendo e mantendo contato.

Também se observam, nesta interação, os atos dialógicos perceber e reconhecer. Quando, a partir da fala 16, a professora passa a questionar os alunos sobre os perigos e benefícios do cálcio, ela adota uma postura investigativa, de interesse e curiosidade, buscando perceber ou identificar as concepções dos alunos. Perceber, de acordo com Alro e Skovsmose (2006), significa, além de outros aspectos, descobrir algo que não se conhece; e, quando a professora questiona sobre a "dureza da água", ela está procurando compreender o que significa o termo em questão. $\mathrm{O}$ ato de perceber vem acompanhado de questões que buscam explicações e investigações e, geralmente, são questões abertas, onde o interlocutor questiona sobre algo de que não sabe a resposta ou não conhece. Em 6 [o que mais você sabe deste rio?], 16 [Perigosa? Por que A9?], 19 [o que é isso?] e 24 [explique melhor...], a professora questiona no sentido de perceber e reconhecer as ideias e conhecimentos dos alunos. Estas questões, e as contribuições oriundas destas, auxiliam os 
alunos a elaborarem suas concepções, e a professora e os outros participantes a perceberem e reconhecerem o objeto de pesquisa.

As contribuições dos alunos ainda podem ser consideradas como um tipo de posicionamento, visto que, nelas, os alunos expõem o que consideram sobre a importância do Rio Limoeiro e sobre a importância do cálcio. Nesta interação, não consideramos que os alunos estejam defendendo suas ideias, porém tornam público o que pensam a respeito destes elementos. A fala de A13 em 23 [Mas o cálcio também é bom para a saúde] evidencia bem este ato. A aluna posicionase diferentemente do que vinha sendo argumentado até o momento. A articulação das duas perspectivas faz com que a professora realize uma síntese final em 28 [então o cálcio é bom, mas não pode ser em excesso certo?] utilizando as duas perspectivas. Estes posicionamentos conduzem os alunos a atribuírem importância à investigação da situação: analisar a concentração de cálcio em diferentes profundidades de um rio importante para a cidade. Deste modo, interpretamos estes atos como posicionar-se.

$\mathrm{O}$ ato de reformulação pode ser observado na fala 11 [certo... a água do Rio Limoeiro é uma das fontes de abastecimento de Londrina. Uma das né? Tem outras. Alguém sabe de mais alguma?], quando a professora indica um entendimento e convida os demais a uma reflexão. O último ato que inferimos estar presente nesta interação é o ato de avaliar, que, segundo Alro e Skovsmose (2006), consiste em um conselho, um apoio, elogio, crítica ou feedback. As falas da professora em 11 [certo... a água do Rio Limoeiro é uma das fontes de abastecimento de Londrina], em 13 [certo... obrigada] e 30 [ok pessoal...] são classificadas como uma avaliação da professora, aceitando as contribuições construídas em interação.

A presença destes atos dialógicos indica que esta interação contempla aspectos considerados importantes para a promoção do diálogo, conforme argumentações de Alro e Skovsmose (2006): propõe aos alunos uma investigação, contempla a imprevisibilidade, expondo os alunos ao "correr riscos", ao mesmo tempo em que promove a igualdade entre os participantes. . Diante do exposto, consideramos que esta interação constitui um diálogo e, deste modo, favorece o desenvolvimento do indivíduo.

Após esta interação e a leitura do texto, os alunos, sob a supervisão da professora, formulam o problema de estudo, estabelecem as variáveis, e decidem observar a tendência dos dados (Tabela 1) visando inferir sob o modelo que melhor se ajuste a estes dados. A Interação 2 apresenta a conversação ocorrida entre os alunos de um grupo, logo após a representação gráfica da tendência dos dados.

\section{Interação 2}

A9: olha aqui... no começo parece linear... [mostrando os três primeiros pontos da representação gráfica da tendência dos dados].

A10: mas aqui tá longe... não dá 'prá' ser uma reta... [mostrando o último ponto representado na tendência dos dados].

A9: ah... dá "prá vê" se é linear. É só ver a variação. Se for igual é linear né?

A10: a taxa de variação? Como assim?

A9: é... a variação da concentração em relação à profundidade.... se for constante é linear...

A10: então vamos calcular... 
Neste momento, o grupo realiza a análise dos dados para orientá-los na definição da hipótese, encontrando a taxa média da concentração de cálcio em relação à profundidade, apresentada na Tabela 2 .

Tabela 2. Taxa média da concentração de cálcio em relação à profundidade do rio Limoeiro

\begin{tabular}{|c|c|c|}
\hline \multirow{2}{*}{$\begin{array}{l}\text { Profundidade }(p) \\
(\mathrm{cm})\end{array}$} & \multirow{2}{*}{$\begin{array}{c}\text { Concentração de cálcio } C(p) \\
(\mathrm{g} / \mathrm{cm} 3)\end{array}$} & \multirow{2}{*}{$\begin{array}{l}\Delta \mathbf{C} \\
\Delta \mathrm{p}\end{array}$} \\
\hline & & \\
\hline 30 & 2,95839 & $-0,011$ \\
\hline 90 & 2,3163 & $-0,011$ \\
\hline 150 & 1,64139 & $-0,006$ \\
\hline 210 & 1,2647 & $-0,006$ \\
\hline 330 & 0,6041 & 0,002 \\
\hline
\end{tabular}

Fonte: elaborado pelos autores a partir de anotações dos alunos.

De posse destes valores, os alunos continuam a discussão:

A9: ó... parece linear porque a variação é "quase" constante. As duas primeiras são iguais, depois as outras duas também são. Será que não é linear? [indicando a terceira coluna da tabela 2].

A10: Mas dá um salto de -0,011 para-0,006. ...é grande... não pode ser.

A8: é... parece muito... E se fosse linear aí ia chegar um momento, em uma profundidade, que seria negativa...não pode. Tá mais parecendo exponencial, não é? Aquela que vai diminuindo, diminuindo, mas não chega no zero.

A9: ó ... a gente tem no livro: A taxa de variação é proporcional à quantidade... [escreve $\left.\frac{\Delta \mathrm{C}}{\Delta \mathrm{p}} \cong k C\right]$.

\section{Análise da Interação 2}

Caracterizamos esta interação como um diálogo, tendo em vista que os alunos levam em consideração as contribuições uns dos outros, complementando-as ou desafiando-as. Consideramos que os alunos estabelecem contato chamando a atenção um do outro para o que estavam observando, com expressões do tipo “olha aqui”, “né?”, “não é?”, “ó”. O tipo de conversação indica que estão "falando a mesma língua", que estão preocupados com o entendimento da situação e a elaboração da hipótese. $\mathrm{O}$ ato de perceber se faz presente quando, em 35, o aluno A9 fala de taxa de variação, conduzindo A10 a pensar nesta hipótese, e, também, na fala 39, quando A9 chama a atenção para a possibilidade de ser linear. $\mathrm{O}$ ato de posicionar-se está presente o tempo todo nesta interação, cada aluno expondo sua perspectiva e compreensão da situação, e, ainda, aceitando a do outro quando considera plausível. A10 e A8 argumentam, em 40 e 41, que não consideram possível representar esta tendência dos dados como uma função linear; e, mesmo sem declarar que concordou com as considerações dos colegas, na fala 42, o aluno A9 aceita a hipótese de que os dados não podem ser representados (para a situação em estudo) por uma função do primeiro grau e, assim, parte para a procura de uma 'lei’ que rege a situação. 
Além disso, os alunos reconhecem, em 35, 36 e 37, que podem utilizar a taxa de variação para verificar se a função pode ser representada por uma função linear. Os discursos destes alunos, nas falas 33, 34 e 41, ainda podem ser considerados como pensar alto, como se estivessem falando consigo mesmos. Este ato faz com que o outro reavalie sua perspectiva ou argumente contrário ao que o colega está pensando. Ainda observamos, na fala 37, uma reformulação de A9 da sua fala emitida em 35. A declaração de A10 em 40 [Mas dá um salto de -0,011 para -0,006.... é grande... não pode ser] nos sugere um desafio, onde A10 propõe uma mudança de perspectiva, sugerindo que a situação não pode ser representada por uma função linear.

A9 inicia a conversação convidando seus colegas e a si mesmo a observarem o que ocorre com a tendência dos dados, conjecturando que a situação pode ser aproximada por uma função linear [olha aqui... no começo parece linear....]. As contribuições de A10 (em 35: mas aqui tá longe... não dá "prá" ser uma reta... e em 40: Mas dá um salto de -0,011 para-0,006. ... é grande... não pode ser) e de A8 (em 41: é... parece muito... E se fosse linear aí ia chegar um momento, em uma profundidade, que seria negativa... não pode. Tá mais parecendo exponencial, não é?) conduzem o grupo a compreender que a situação fica melhor representada considerando que a taxa de variação não é constante.

Ainda podemos observar que, nesta interação, as ideias dos alunos são respondidas e/ ou completadas pelos outros; os participantes do grupo interagem no sentido de responderem às questões dos colegas e o grupo chega a um consenso de que a variação da concentração em relação à profundidade não deve ser considerada constante.

A partir das características dessa interação, podemos inferir que estes atos dialógicos permitem estabelecer contato, perceber, posicionar-se, reconhecer, pensar alto e reformular. Além disso, esta interação também propõe uma investigação, expõe os alunos ao risco ao mesmo tempo em que promove a igualdade. Neste sentido, pode também ser caracterizada como um diálogo.

Um problema revelado nesta Interação 2 é que os alunos não constroem, por meio da observação dos dados, a hipótese de que a taxa de variação da concentração é proporcional à concentração em cada profundidade. $\mathrm{O}$ grupo chega apenas à conclusão de que a variação não poderia ser considerada constante; e, pensando em um modelo exponencial, busca, no livro, um modelo que resultaria na hipótese construída. Deste modo, a partir da ideia do livro, o grupo considera a hipótese $\frac{\Delta \mathrm{C}}{\Delta \mathrm{p}} \cong k C$, ou seja, a variação da concentração de cálcio em relação à profundidade é proporchonal à quantidade de cálcio, sem, no entanto, terem construído esta hipótese. Como neste momento a professora estava acompanhando este grupo, iniciou uma conversação no sentido de conduzi-los a um entendimento do que estavam utilizando.

Acompanhando os demais grupos, a professora pôde observar que a definição da hipótese representava dúvida para todos, e, diante disto, realizou a intervenção, apresentada na sequência.

\section{Interação 3}

Prof: pessoal, o que vocês observaram na tendência dos dados?

A7: poderia ser uma reta "prof" mas não pode... [o aluno explicou os motivos para esta conclusão]: a gente viu que poderia ser linear... com estes dados... mas não pode porque i a ficar negativa em uma profundidade... não pode. Tem que chegar perto do zero, mas não pode dar zero. Então a gente viu no livro. 
Prof: tá. Vocês estão certos. A tendência dos dados sugere uma função do primeiro grau. O cálculo da taxa de variação média confirma esta bipótese, ou seja, a taxa de variação média é praticamente constante. Mas pelo que a gente conbece do fenômeno, por tratar-se de uma situação real, a gente sabe que não pode utilizar esta hipótese. [Ao mesmo tempo em que a professora falava escrevia no quadro uma tabela com os valores da concentração, da profundidade e da taxa de variação média].

Prof: Então, o que a gente pode fazer agora é analisar se a taxa de variação da concentração em relação à profundidade é proporcional à concentração. Se for, então podemos utilizar o modelo $\frac{\Delta \mathrm{C}}{\Delta \mathrm{p}}=k C$.

[Como os alunos reagiram demonstrando não-entendimento, a professora continuou explicando e escrevendo no quadro.]

Prof: assim ó: vocês já calcularam $\frac{\Delta \mathrm{C}}{\Delta \mathrm{p}} \quad$ certo? Agora isolem $k$, como fica o modelo $\frac{\Delta \mathrm{C}}{\Delta \mathrm{p}}=k C$ ?

A9: dividindo...

Prof: você não vale... [rindo]. Eu já expliquei prá eles. Olha pessoal, é isso que A9 falou, dividam todas as variações por cada concentração correspondente e se for constante significa que é proporcional a $C$. Aí a gente pode usar a hipótese

$\frac{\Delta \mathrm{C}}{\Delta \mathrm{p}}=k C$, ok? Onde ké a constante de proporcionalidade.

A9: vai dar certo... [rindo].

Prof: ok. ele já contou... Mas se não desse constante a gente teria que analisar outras hipóteses, ok?

\section{Análise da Interação 3}

Consideramos que, nesta interação, a professora não se preocupa em investigar o ponto de vista dos alunos, sendo nítida a sua intenção de fazer com que os alunos percebam a necessidade de analisar a hipótese antes de aceitá-la e reconhecerem o conceito matemático subjacente à hipótese adotada. Esta interação não foi caracterizada por nós como constituinte de um diálogo, como o caracterizado por Alro e Skovsmose (2006), visto que a questão elaborada pela professora na fala 43, apesar de sugerir que estaria interessada na perspectiva dos alunos, tinha o claro objetivo de iniciar suas argumentações. No restante da interação, a professora orienta os alunos no sentido de introduzir os conceitos matemáticos necessários para a solução do problema.

Vale salientar que, apesar de não ser caracterizada como um diálogo, a fala da professora em 45 revela considerações importantes para o desenvolvimento de atitudes de reflexão quanto à situação-problema e a elaboração de hipóteses; pois ela fala, implicitamente, sobre a importância de não se orientar apenas pelo que apresenta a tendência dos dados, observando que é essencial que pensem no conjunto, que analisem o fenômeno como um todo, antes de adotar uma perspectiva. Entretanto, esta é a única fala que sugere uma característica de diálogo. Faz parte das ações dos alunos em atividades de Modelagem Matemática: questionar, problematizar, sugerir, bem como analisar os dados, a situação e todas as suas restrições, considerando-as quando julgarem necessário e pertinente. Nesta fala, a professora enfatiza a necessidade destas ações em atividades tanto em Modelagem Matemática como na resolução de qualquer situação-problema. 
Neste sentido a professora conduz os alunos para que mudem o procedimento, procurando construir a hipótese ao invés de recorrerem a um modelo pronto do livro, sem entenderem o motivo de estar utilizando este modelo. A professora procura fazer com que entendam o motivo pelo qual a hipótese pode ser esta que estão sugerindo. Assim, sugere que mudem a direção, primeiro analisando os dados e, depois, concluindo que os dados sugerem esta hipótese.

A professora assume, nitidamente, sua posição de "autoridade" em sala de aula, questionando os alunos e avaliando suas respostas com outras questões, sem considerar o ponto de vista dos alunos. O padrão de interação constitui, praticamente, um jogo de perguntas.

Um fato importante para esta atividade é a constatação dos alunos de que, apesar de os dados sugerirem uma aproximação para um modelo linear, este modelo não poderia ser aceito, visto que trabalham com variáveis que não aceitam valores negativos. Lógico que o Domínio da função poderia ser limitado, porém, a professora não discutiu este assunto com os alunos, provavelmente passando-lhe despercebida esta possibilidade.

A argumentação dos alunos para o descarte do modelo linear, vai ao encontro do propósito da Modelagem Matemática enunciado por Bassanezi (2002, p. 56): “obter uma relação funcional que comporte em seus parâmetros qualidades ou significados inerentes ao fenômeno analisado e para isto se faz necessário um estudo detalhado do próprio fenômeno". O entendimento da situação-problema conduz os alunos à refutação da primeira hipótese, tendo em vista que o fenômeno estudado não comporta valores negativos para a concentração. Esta refutação é uma característica da Modelagem Matemática: o problema em estudo trata de uma situação real na qual o fenômeno como um todo deve ser analisado antes de se aceitar uma hipótese matemática válida.

Uma das ações do aluno em atividades de modelagem em sala de aula consiste em entender a situação e formular hipóteses, não apenas com referência aos dados, e sim levando em consideração as restrições que o fenômeno apresenta. A oportunidade de estabelecer hipóteses com base no conhecimento da situação é possível graças às características da atividade: uma situação 'reconhecível' pelos alunos e do interesse de um engenheiro ambiental.

Com a intervenção da professora, os grupos consideraram a hipótese $\frac{\Delta C}{\Delta \mathrm{p}} \cong k C \quad \mathrm{e}$ a reescrevem utilizando a ideia de variável contínua, apresentando a Equação Diferencial $\frac{d C}{d p}=k C$, encontrando $C p=N . e^{k p}, N e k \in R$, determinando, em seguida, os parâmetros $N$ e $k$. Uma vez determinado o modelo, os alunos realizaram a validação e apresentaram o resultado à turma e suas considerações sobre o modelo e o desenvolvimento da atividade.

Conforme comentamos no início da descrição desta atividade, o tema de estudo despertou o interesse destes alunos muito provavelmente por abarcar uma situação com referência no cotidiano do ser humano, e, particularmente, de interesse profissional de um engenheiro ambiental. Neste sentido, a 'escolha' do tema de estudo contribui para o delineamento das interações, visto que a participação do aluno nestas interações, seus argumentos, suas questões, suas preocupações e interesse, são influenciados pelo conhecimento da situação em estudo ou pela possibilidade de 'imaginar/reconhecer' esta situação, bem como pelo encaminhamento dado à atividade pela professora. 


\section{Considerações finais}

A análise da atividade descrita neste texto nos leva a inferir que a utilização da Modelagem Matemática em sala de aula constitui uma importante ferramenta para o desenvolvimento do indivíduo, e, neste sentido, endossamos as argumentações a favor da sua inserção na aula de matemática.

Observou-se, no decorrer da atividade, que algumas ações dos alunos não são exclusivas de atividades interativas, porém, a diferença reside no fato de que, em interação, estas ações são, muitas vezes, explicitadas para o outro, atuando como auxiliadoras e, ao mesmo tempo, atuando como reorganizadoras do pensamento, promovendo a estruturação e novas aprendizagens. Este fato se deve à necessidade de o indivíduo se fazer entender, e, neste ato, o indivíduo realiza uma reflexão do seu pensamento. Enquanto os alunos realizam seus procedimentos em grupo, eles falam a respeito do que fazem, perguntando, e, muitas vezes, explicando o que estão fazendo. Suas falas, além de acompanharem a realização da atividade, a orientam, uma vez que, ao deparar-se com sua fala ou sua escrita, o aluno pode observar um procedimento equivocado e corrigi-lo por si só, como se fosse uma interação consigo mesmo.

Assim, ainda que a importância da interação durante atividades de Modelagem Matemática já tenha sido apontada em pesquisas anteriores, a contribuição desta pesquisa para a área de Educação Matemática encontra-se na identificação de interações com qualidades consideradas, por Alro e Skovsmose (2006, p. 142), como "fontes de aprendizagem”.

A análise da aprendizagem dos conceitos matemáticos no decorrer da disciplina foi realizada por meio de provas e da observação sistemática realizada durante o desenvolvimento da atividade de resolução de problemas.

Em relação às provas que continham problemas da área de atuação do estudante, foram realizadas tanto individualmente quanto em duplas. $\mathrm{O}$ aluno não tinha a resposta de imediato e as questões caracterizaram-se verdadeiros "problemas" As avaliações em dupla, que normalmente aconteciam antes das avaliações individuais, foram deveras importante para o desenvolvimento de habilidades de cooperação e, muitas vezes, oportunizaram o aprendizado de conceitos ainda em formação. A resolução dos problemas deu-se de forma satisfatória, levando-nos a inferir que os conceitos matemáticos subjacentes foram apreendidos.

Considerando que, de modo geral, turmas de disciplinas de Matemática em séries iniciais de cursos de Engenharia são mais numerosas do que a pesquisada neste trabalho, a particularidade da pesquisa de ser desenvolvida com 14 alunos, sendo, a pesquisadora, a própria professora da disciplina, pode ser superada em pesquisas futuras. 


\section{Agradecimentos}

Agradecemos a Allan Marcel Nishioka (in memoriam), Ana Carolina Pierotti Jacobs, Fernanda Bezerra Mangili, Livia Deliberador Francescon, Marcela Arfelli Silva, Mateus Mesquita de Paula Alves Nunes, Matheus Henrique da Silva, Michel Iuri Caetano, Monica Hirata Bertachi, Nariane Marselhe Ribeiro Bernardo, Noelle Santos Salsa, Paula Fernanda Almeida Goncalves, Rafael Coelho Ciciliato e Vitor Manoel Nogueira Alvares, meus alunos e participantes desta atividade de Modelagem Matemática.

\section{Referências}

ALMEIDA, L. M. W.; FERRUZZI, E. C. Uma aproximação socioepistemológica para a modelagem matemática. Alexandria: revista de educação em ciência e tecnologia, Florianópolis, v. 2, n. 2, p. 117-134, 2009. Disponível em: < http://alexandria.ppgect.ufsc.br/ files/2012/03/lourdes.pdf>. Acesso em: 27 jan. 2015.

ALRO, H.; SKOVSMOSE, O. Diálogo e aprendizagem em educação matemática. Belo Horizonte: Autêntica, 2006.

BASSANEZI, R. C. Ensino aprendizagem com modelagem matemática: uma nova estratégia. São Paulo: Contexto, 2002.

BISOGNIN, E.; BISOGNIN, V.; ALONSO RAYS, O. Modelo matemático da concentração de cocaína no organismo humano: modelagem matemática no ensino de Matemática.

Educação Matemática em Revista, Porto Alegre, v. 6, n. 6, p. 81-88, 2004.

BORBA, M. C.; MALHEIROS, A. P. S. Diferentes formas de interação entre internet e modelagem: desenvolvimento de projetos e o CVM. In: BARBOSA, J. C.; CALDEIRA, A. D.; ARAÚJO, J. L. (Org.). Modelagem matemática na educação matemática brasileira: pesquisas e práticas educacionais. Recife: SBEM, 2007. v. 1, p. 195-214.

BORSSOI, A. H. A Aprendizagem significativa em atividades de modelagem matemática como estratégia de ensino. 2004. 140 f. Dissertação (Mestrado em Ensino de Ciências e Educação Matemática) - Universidade Estadual de Londrina, Londrina, 2004.

CHINNAPPAN, M.; THOMAS, M. O. J. Teachers' function schemas and their role in modelling. Mathematics Education Research Journal, Dordrecht, v. 15, n. 2, p. 151-170, 2003.

FERRUZZI, E. C. Interações discursivas e aprendizagem em modelagem matemática. 2011. 228 f. Dissertação (Mestrado em Ensino de Ciências e Educação Matemática) - Centro de Ciências Exatas, Universidade Estadual de Londrina, Londrina 2011.

FOX, J. L. A justification for mathematical modelling experiences in the preparatory classroom. In: ANNUAL CONFERENCE OF THE MATHEMATICS EDUCATION RESEARCH GROUP OF AUSTRALASIA, 29., 2006, Canberra. Proceedings... Disponível em: <http://www.merga.net.au/documents/RP232006.pdf>. Acesso em: 27 jan. 2015. 
Ferruzzi, E. C.; Almeida, L. M. W.

OLIVEIRA, A. M. P.; CAMPOS, I. S.; SILVA, M. S. As estratégias do professor para desenvolver modelagem matemática na sala de aula. Boletim GEPEM, Rio de Janeiro, v. 55, n. 3, p. 175-192, 2009.

SANT'ANA, M. F. Modelagem de experimento e ensino de cálculo. In: BARBOSA, J. C.; CALDEIRA, A. D.; ARAÚJO, J. L. (Org.). Modelagem matemática na educação matemática brasileira: pesquisas e práticas educacionais. Recife: SBEM, 2007. v. 1, p. 149160.

SANTOS, L. M. M.; BISOGNIN, V. Experiências de ensino por meio da modelagem matemática. In: BARBOSA, J. C.; CALDEIRA, A. D.; ARAÚJO, J. L. (Org.). Modelagem matemática na educação matemática brasileira: pesquisas e práticas educacionais. Recife: SBEM, 2007. v. 3, p. 99-114.

SKOVSMOSE, O. Educação matemática crítica: a questão da democracia. Campinas: Papirus, 2001.

VIGOTSKY, L. S. Pensamento e linguagem. São Paulo: Martins Fontes, 1993.

ZBIEK, R.; CONNER, A. Beyond motivation: exploring mathematical modeling as a context for deepening students' understandings of curricular mathematics. Educational Studies in Mathematics, Dordrecht, v. 63, n. 1, p. 89-112, 2006. 